\title{
Practice of the Caesarean Section in Four Maternities in Benin Using Robson Classification
}

\section{Benjamin Hounkpatin1, Moufalilou Aboubakar1 ${ }^{*}$, Patrice Dangbemey1, Veronique Tognifode1, Clémence Schantz ${ }^{2}$, Alexandre Dumont ${ }^{2}$, René-Xavier René-Perrin1}

${ }^{1}$ University-Associated Hospital for the Mother and Child-Lagoon (CHU-MEL), Cotonou, Benin

${ }^{2}$ Population and Development Center-Development Research Institute, Paris, France

Email: ^moufaliloua@yahoo.fr

How to cite this paper: Hounkpatin, B., Aboubakar, M., Dangbemey, P., Tognifode, V., Schantz, C., Dumont, A. and René-Perrin, R.-X. (2020) Practice of the Caesarean Section in Four Maternities in Benin Using Robson Classification. Open Journal of Obstetrics and Gynecology, 10, 65-75.

https://doi.org/10.4236/ojog.2020.101006

Received: November 18, 2019

Accepted: January 5, 2020

Published: January 8, 2020

Copyright $\odot 2020$ by author(s) and Scientific Research Publishing Inc. This work is licensed under the Creative Commons Attribution International License (CC BY 4.0).

http://creativecommons.org/licenses/by/4.0/

(c) (i) Open Access

\begin{abstract}
Objective: To measure for each of the ten (10) groups of women defined in Robson's classification, the cesarean section rate, group size and its contribution to the overall cesarean section rate in four maternities in Benin. Methods: This was a retrospective study over a period of 3 years, from January 1 , 2014 to December 31, 2016. Two workshops were organized for training in data collection and interpretation of results. Results: A total of 5442 files were included for the four health facilities during the study period. The overall cesarean section rate was $43.9 \%$. The most represented group (30.3\%) was multiparous women without scarred uterus, with a single term fetus, in cephalic presentation, and spontaneous labour (Group 3). The largest contributor to the overall cesarean section rate was that of multiparous women with at least one uterine scar with a single fetus, eventually in cephalic presentation (Group 5) with 29.5\%. Conclusion: Caesarean section rates are high in groups of women with a favourable prognosis for vaginal delivery. It is also high in women with scarred uterus (Group 5).
\end{abstract}

\section{Keywords}

Caesarean Section, Robson Classification, Benin

\section{Introduction}

Caesarean section when medically justified can prevent maternal and perinatal morbidity and mortality [1]. According to WHO, at the population level, a Caesarean section rate greater than $10 \%$ is not associated with a reduction in mater- 
nal and neonatal mortality rates [2] [3]. Over the past three decades, there has been a significant increase in caesarean section rates, particularly in developed countries [4], which has led some authors to speak of an "outbreak" of caesarean section [5] [6]. WHO in two multi-country surveys on maternal and perinatal health showed an increase in hospital cesarean section rates from $26.4 \%$ in 2004-2008 to $31.2 \%$ in 2010-2011 [7] [8] [9].

However, population cesarean section rates remain low in many sub-Saharian African countries [1] where there is still great inequality of access to cesarean section between the poorest and richest households.

In Benin, the national cesarean section rate is $9.3 \%$ in 2016 according to statistics obtained from the relevant services of the Ministry of Health.

To analyse Caesarean section rates and facilitate geographical or temporal comparisons at the service level, different classifications exist. In 2011, after a systematic review of the systems used to classify Caesarean sections, WHO concluded that Robson's classification is the system that best meets current needs both locally and internationally [10] [11]. He proposed Robson's classification as a model for evaluating, monitoring and comparing cesarean section rates for each facility and between facilities.

This classification, which has been widely used since then, offers many advantages [12]. It is simple, robust, reproducible, clinically relevant and prospective and all women admitted for childbirth can be immediately classified into one of the 10 groups. It allows for the comparison and analysis of cesarean section rates within and between these groups and the contribution of each group to the overall cesarean section rate. It applies to both developed and developing countries [2].

In Benin, many studies have been carried out on caesarean section. But none has yet evaluated the practice of cesarean section according to Robson's classification. The objective of this work was to measure for each of the 10 groups of women defined in Robson's classification, the cesarean section rate, the size of the group and its contribution to the overall cesarean section rate in four maternal health facilities in Benin.

\section{Materials and Methods}

This is a retrospective study over a three-year period, from January 1, 2014 to December 31, 2016. It was conducted in four health facilities in Benin, including one private facility: University-associated Hospital for the Mother and Child-Lagoon (CHU-MEL), Biosso clinic, University-associated Hospital of Borgou/Alibori (CHDU-B/A) and the Regional Hospital Dassa (HZD). These units cover the three levels of the Benin health pyramid: level 1 of reference corresponds to the regional hospital, level 2 corresponds to the departmental hospital and level 3 to the national hospital. The private clinic has been assimilated to a level 1 due to its technical platform and human resources. With the exception of the private clinic, all three other public health facilities are approved for 
free Caesarean section.

As part of this study, two workshops were organized. The first, held on 14 March 2017 before the start of the study, was devoted to training actors on data collection and analysis of results. Data collection took place from March to July 2017. For each health facility, the collection was carried out by a pair including a medical student in the final year associated either with a midwife or an obstetrician gynaecologist. The sample for each of the three public sector health facilities is composed of the first 500 births each year (2014, 2015 and 2016). For the private clinic, which registered less than 500 births per year, all births were included.

The inclusion criteria were a live birth, a gestational age of at least 28 weeks of amenorrhea (AW) or a birth weight of at least $1000 \mathrm{~g}$. The data were extracted from the women's medical records or birth room registers according to the media used by each health facility. They covered parity, number of fetuses, past history of cesarean section, term of pregnancy, presentation of the fetus, mode of entry into labour. A pregnancy was said to be at term for a gestational age $>$ 36AW6 days or, if there was no gestational age, for a foetal weight $>2500 \mathrm{~g}$. The data thus collected were transferred and compiled for processing.

Women admitted for the management of a complication after childbirth in another health facility, women admitted for late abortion and those with incomplete medical record were not included.

A second training session held on Thursday, July 20, 2017, was devoted to the analysis and interpretation of the results collected from the four sites. In Robson's classification, Groups 1 to 4 correspond to low-risk women since they are full-term women with no history of cesarean section and a single fetus in cephalic presentation. Groups 5 to 10 , on the other hand, correspond to women at high risk of cesarean section.

We calculated for all four maternity hospitals and for each hospital:

- The relative size of each group (number of women in the group divided by the total number of women);

- Caesarean section rate (number of women who delivered by caesarean section in the group divided by the number of women in the group);

- The relative contribution of each group to the overall Caesarean section rate (number of Caesarean sections divided by the total number of Caesarean sections).

The study obtained a favourable opinion from the National Committee for Ethics and Health Research of Benin (CNERS) (opinion n ${ }^{\circ} 66 / M S / D C / S G M /$ DRFMT/CNERS/SA).

\section{Results}

A total of 5442 files were included for the four health facilities during the study period. The majority were between 24 and 29 years old (Table 1). The relative size of each group (Table 2). 
Table 1. Distribution by age.

\begin{tabular}{ccc}
\hline Age (years) & Number & Percentage \\
\hline Less than 20 & 512 & 09.4 \\
$20-24$ & 1098 & 20.1 \\
$24-29$ & 1449 & 26.8 \\
$30-34$ & 1212 & 22.2 \\
$35-39$ & 764 & 14.0 \\
40 and more & 351 & 06.4 \\
Not declared & 56 & 01.1 \\
Total & 5442 & 100 \\
\hline
\end{tabular}

Table 2. Data compilation of the four health facilities.

\begin{tabular}{cccccccc}
\hline & $\begin{array}{c}\text { Number of } \\
\text { women }\end{array}$ & $\begin{array}{c}\text { Vaginal } \\
\text { route }\end{array}$ & C-section & $\begin{array}{c}\text { Size of } \\
\text { group }\end{array}$ & $\begin{array}{c}\text { C section } \\
\text { rate }\end{array}$ & $\begin{array}{c}\text { Absolute } \\
\text { Contribution }\end{array}$ & $\begin{array}{c}\text { Relative } \\
\text { Contribution }\end{array}$ \\
\hline Group 1 & 1118 & 702 & 416 & 20.54 & 37.21 & 7.64 & 17.41 \\
Group 2 & 238 & 67 & 171 & 4.37 & 71.85 & 3.14 & 7.15 \\
Group 3 & 1652 & 1268 & 384 & 30.36 & 23.24 & 7.06 & 16.07 \\
Group 4 & 251 & 144 & 107 & 4.61 & 42.63 & 1.97 & 4.48 \\
Group 5 & 857 & 150 & 707 & 15.75 & 82.50 & 12.99 & 29.58 \\
Group 6 & 95 & 32 & 63 & 1.75 & 66.32 & 1.16 & 2.64 \\
Group 7 & 230 & 89 & 141 & 4.23 & 61.30 & 2.59 & 5.90 \\
Group 8 & 351 & 222 & 129 & 6.45 & 36.75 & 2.37 & 5.40 \\
Group 9 & 74 & 2 & 72 & 1.36 & 97.30 & 1.32 & 3.01 \\
Group 10 & 576 & 376 & 200 & 10.58 & 34.72 & 3.68 & 8.37 \\
Total & 5442 & 3052 & 2390 & 100 & 43.92 & 43.92 & 100 \\
\hline
\end{tabular}

Overall, the most represented group was that of multiparous women without scarred uterus with a single fetus, eventually in cephalic presentation and spontaneous labour (Group 3) followed by nulliparous women with a single fetus, in term in cephalic presentation and spontaneous labour (Group 1) and all multiparous women with at least one uterine scar with a single fetus, in term in cephalic presentation (Group 5) in respective proportions of $30.3 \%, 20.5 \%$ and $15.7 \%$.

Considering the health facilities taken alone, the same order is found in each of the three public facilities. On the other hand, in the private clinic, the most represented group was Group 3 followed by Group 5 and multiparous women without scared uterus, with a single fetus, eventually in cephalic presentation and induced labour or cesarean section before labour (Group 4) in proportions of $22.6 \%, 19.7 \%$ and $16.4 \%$ respectively.

The groups at low risk of cesarean section include all women at term with a single fetus in cephalic presentation and without scared uterus (Groups 1 to 4) 
and accounted for $59.8 \%$ of births.

Caesarean section rate (Table 3 ).

The overall cesarean section rate for all four formations was $43.9 \%$. Cesarean section rates are quite similar in the three public health facilities: $41.7 \%$ at the regional Hospital of Dassa, $42.1 \%$ at the CHU-MEL and $44.9 \%$ at the $\mathrm{CHDU}-\mathrm{B} / \mathrm{A}$ in Parakou. The highest caesarean section rate is recorded in the private clinic (48.6\%).

Relative contribution (Table 4).

Overall, the largest contributor to the cesarean section rate is the group of low-risk women (Groups 1 to 4 ) representing $45.1 \%$ of cesarean sections followed by multiparous women with a scarred uterus (Group 5) with $29.5 \%$.

The relative contribution of low-risk groups $(1-4)$ is $45.2 \%$ and the largest contributor is Group 2 (71.8\%).

Table 3. Section rate per health facilities regarding each group.

\begin{tabular}{ccccc}
\hline & CHU-MEL & Hôpital de Dassa & CHDU-B/A & Clinique Biosso \\
\hline Group 1 & 36.8 & 35.6 & 43.2 & 23.9 \\
Group 2 & 57.4 & 94.4 & 93.1 & 70.8 \\
Group 3 & 14.1 & 31.9 & 26.3 & 10.1 \\
Group 4 & 26.7 & 88.9 & 72.7 & 35.0 \\
Group 5 & 73.9 & 75.8 & 92.1 & 92.6 \\
Group 6 & 68.8 & 62.1 & 64.1 & 81.8 \\
Group 7 & 72.7 & 43.6 & 57.3 & 81.5 \\
Group 8 & 52.7 & 26.9 & 36.5 & 70.6 \\
Group 9 & 100 & 100 & 93.3 & 100 \\
Group 10 & 38.4 & 34.1 & 23.1 & 47.3 \\
Total & 42.1 & 41.7 & 44.9 & 48.6 \\
\hline
\end{tabular}

Table 4. Relative contribution of each group per health facility.

\begin{tabular}{ccccc}
\hline & CHU-MEL & Hôpital de Dassa & CHDU-B/A & Clinique Biosso \\
\hline Group 1 & 19.0 & 19.1 & 22.6 & 5.6 \\
Group 2 & 5.5 & 2.7 & 4.0 & 19.7 \\
Group 3 & 8.5 & 28.4 & 19.6 & 4.7 \\
Group 4 & 1.9 & 3.9 & 2.4 & 11.8 \\
Group 5 & 33.5 & 23.3 & 26.2 & 37.6 \\
Group 6 & 1.7 & 2.9 & 3.7 & 1.9 \\
Group 7 & 7.6 & 3.9 & 7 & 4.7 \\
Group 8 & 6.2 & 7.6 & 4.6 & 2.6 \\
Group 9 & 2.1 & 3.6 & 4.2 & 1.9 \\
Group 10 & 13.9 & 4.7 & 5.8 & 9.4 \\
Total & 100 & 100 & 100 & 100 \\
\hline
\end{tabular}




\section{Discussion}

Caesarean section is the most common surgical procedure in obstetrics. Its technique has been simplified and improved over time and it has become safer. In this study, the overall cesarean section rate was $43.9 \%$. The most represented group was multiparous women without scarring uterus with a single fetus, eventually in cephalic presentation and spontaneous labor (Group 3) with $30.3 \%$. The largest contributor to the cesarean section rate was multiparous women with at least one uterine scar with a single fetus, eventually in cephalic presentation (Group 5).

Overall Caesarean section rate

The overall Caesarean section rate found in our study is $43.9 \%$ for several reasons.

The first is that this is a rate of reference health facilities that manage higher risks. They receive patients evacuated from lower-level structures, which leads to a concentration of pathologies. As these hospitals are fields of training for doctors specialising in gynaecology and obstetrics, it is likely that, in order to acquire surgical skills or because of lack of experience, some caesarean section indications are misused by learners leading to caesarean sections when they have escaped the control of the senior on-call staff. A review of cesarean section indications could have invalidated or confirmed this hypothesis. However, in our study we did not consider indications because Robson's classification does not take into account cesarean section indications. Dumont A. [13] in a systematic review of cesarean sections in sub-Saharian Africa had found that $75 \%$ of cesarean sections were of maternal indication and identified six main causes: prolonged labor, retroplacental hematoma, scarred uterus, eclampsia, placenta previa, and vicious presentation. Among these causes, vicious presentation and scarred uterus can sometimes be misrepresented.

This caesarean section rate could also be explained by the measure of free caesarean section in progress in Benin since 2009. In fact, in approved hospitals, caesarean sections are reimbursed up to $100,000 \mathrm{f}$ cfa or about 150 euro. However, the impact of free Caesarean section on the rate of Caesarean section remains controversial. For some authors, it has reportedly led to an increase in the rate of caesarean section [14] [15]. The same observation was made by SOSSA J. and Ouedraogo in their studies conducted respectively at SURU LERE Zone Hospital [15] and Ouidah Hospital [16]. On the other hand, Witter et al. [17] in their study on the impact of measuring free access in several countries (Benin, Mali, Morocco and Burkina Faso) did not find a significant increase in the cesarean section rate higher than the secular trend observed.

Caesarean section rate by group

Groups 1 and 3, due to their obstetrical characteristics, have the best chances of a vaginal delivery.

In our study, the lowest cesarean section rate is found in Group 3 (23.2\%). Martin M. et al. [18] in Switzerland also found the lowest cesarean section rates 
in Groups 1 and 3. It can be assumed that obstetricians are more proactive in dealing with nulliparous women and that, conversely, a history of vaginal delivery is a good prognostic factor for subsequent vaginal delivery. This history prompts obstetricians to give more chances for vaginal delivery, especially in the case of poor equipement labour monitoring.

Florica M. [19] in Sweden, however, noted an increase in the rate of cesarean section in Groups 1 and 3. This author explains this by lowering the tolerance threshold for abnormalities in labour during childbirth, leading to indications of caesarean section being given too early. The increase in maternal pathologies contraindicating vaginal delivery and the increase in maternal demand may also explain this. Stjernholm et al. [20] in their study, however, found that the relative contribution of maternal demand Caesarean section had no impact on the overall Caesarean section rate. In the African context characterized by a natalist trend on the one hand, and given the negative connotation of cesarean section in the popular imagination on the other, personal demand remains low.

The highest rates of cesarean section in low-risk groups are found in Groups 2 and 4 corresponding to labour induction or pre-labor cesarean section. This could also be explained by the existence of medical reasons (medical pathologies such as hypertension) justifying termination of pregnancy. It has been established that labour induction is also a risk factor for cesarean section [21]. Optimization of labour induction indications should reduce cesarean section rates.

The Caesarean section rate in Group 5 is $82.5 \%$ in our study. This rate is higher than that found by WHO in developing countries, which varies from 63.2 to $72.1 \%$ [4] and that reported in a study in Australia [22], 76.3\%. We believe that this rate can be justified mainly by the reluctance of obstetricians to attempt the vaginal approach in the event of a scarred uterus. Vaginal is considered high risk, especially in the context of the lack of optimal labour monitoring in pregnant women who are often admitted in emergency situations with an unfollowed attended or poorly monitored pregnancy and about whom practitioners have little information.

Caesarean section rate regarding public or private status

When considering the caesarean section rate per health facility, the highest rate is recorded in the private clinic. The existence of high rates of cesarean section in private institutions is fairly well documented [23]. Several reasons are mentioned, such as the characteristics of the patients of private structures. They are often intellectuals and/or of a high socio-economic level able to cope with relatively high fees for services. This is the case in the private clinic of our study, which does not apply the free measure. According to Tiziana L. et al. [23] this category of women requests or accepts a caesarean section more often, especially since they have been disappointed in public hospitals (poor management of an earlier pregnancy that sometimes led to the death of the newborn or to maternal or foetal complications). The fear of legal proceedings also leads private sector practitioners to a greater principle of precautions towards those patients, which is more aware of the legislation and more demanding with regard to the cost of 
services.

Finally, unlike the other three health facilities, all parturient women were monitored (recording of fetal cardio rhythm) at the Clinic. The ERCF has been implicated as responsible for an increased risk of cesarean section.

Relative group size

In our overall study, the most represented group was Group 3 followed by Groups 1 and 5.

Together, Groups 1 and 3 account for more than 50\% of our sample and multiparous women represent more than half of it. The same trend was found in a study in Switzerland [22] over a period of 11 years and by WHO in two multi-country surveys on maternal and neonatal health published in 2008 and 2011 [4]. In both WHO surveys, Groups 1 and 3 accounted for $75 \%$ of the study population in developing countries and more than half were multiparous. The preponderance of multiparous women in developing countries reflects the natalist trend, particularly in sub-Saharian Africa.

Group 5 was the 3rd largest group in our study. The same result was found in the WHO surveys [4] which further noted that of the 10 groups, Group 5 is the one that recorded the highest growth between the two studies, going from $63 \%$ to $72 \%$ [4]. The increase in the practice of cesarean section in low-risk women and the high trend towards systematic iterative cesarean section may explain this finding.

Relative contribution

Group 5 remains the largest contributor to the Caesarean section rate after low-risk women (Group 1 - 4) both overall and in individual formations.

This trend is reflected in several studies around the world. According to the WHO, Group 5 is the largest contributor regardless of the level of GDP [4] in the country, thus confirming the high propensity for caesarean section in front of a scarred uterus. Hence the notion of the so-called "domino effect" of Caesarean section: as the rate of Caesarean section increases, more and more women need iterative Caesarean section leading to an increase in the rate of Caesarean section. The increase in maternal and fetal morbidity, the question of professional responsibility for complications, and the changing attitudes of practitioners and patients are reported to be the main reasons for the low rate of vaginal delivery in scarred uteri [24] [25] [26]. According to Zhang J. et al. [25], the vaginal route is only proposed in $28.8 \%$ of cases, while its success rate is $57.1 \%$. For other authors [27] [28], 66\% of scarred uteri are eligible for "uterine testing" but very few are offered this possibility. To reverse this trend, WHO recommends that systematic iterative Caesarean section be discontinued.

In our practice in Benin, caesarean section is almost systematic in term pregnant with a history of at least two caesarean sections. The uterine testing is performed in pregnant women who meet the conditions for its success (cause of cesarean section non-permanent, low segment cesarean section, single fetus, of normal weight in cephalic presentation). 
To reduce the rate of cesarean section in our training it is imperative to reduce the rate of first cesarean section in low-risk groups and in Group 5. According to a WHO multi-country survey, the only country where a downward trend in the overall cesarean section rate was noted was Japan. This decrease was for Groups 1,2 and 5 .

Better training in obstetrics, better companionship of seniors in university-associated maternity, the use of the partogram to monitor labour at birth, detect anomalies and take corrective measures in time, the establishment of service protocols for induction and direction of labour seem to us to be useful measures to achieve this.

\section{Conclusion}

The rate of cesarean section is high in groups of women with a favourable prognosis for vaginal delivery. It is also high in women with scarred uteri (Group 5). Controlling the caesarean section rate requires optimizing the indications for the first caesarean section, increasing vaginal deliveries in low-risk groups, and performing uterine testing in the event of a scarred uterus.

\section{Conflicts of Interest}

The authors declare no conflicts of interest regarding the publication of this paper.

\section{References}

[1] Betran, A.P., Torloni, M.R., Zhang, J.J., Gulmezoglu, A.M. for the WHO Working Group on Caesarean Section (2016) WHO Statement on Caesarean Section Rates. BJOG, 123, 667-670. https://doi.org/10.1111/1471-0528.13526

[2] Betran, A.P., Torloni, M.R., Zhang, J., Yu, J., Deneux-Tharaux, C., Oladapo, O.T., et al. (2015) What Is the Optimal Rate of Caesarean Section at Population Level? A Systematic Review of Ecologic Studies. Reproductive Health, 12, 57. https://doi.org/10.1186/s12978-015-0043-6

[3] Ye, J., Betran, A.P., Torloni, M.R., Mikolajczyk, R.T., Gulmezoglu, A. and Zhang, J. (2015) Association between Caesarean Section and Maternal and Neonatal Mortality: A Worldwide Population-Based Ecologic Study. BJOG, 123, 745-753. https://doi.org/10.1111/1471-0528.13592

[4] Vogel, J.P., Betrán, A.P., Vindevoghel, N., Souza, J.P., Torloni, M.R., Zhang, J., et al. (2015) Use of the Robson Classification to Assess Caesarean Section Trends in 21 Countries: A Secondary Analysis of Two WHO Multicountry Surveys. http://www.thelancet.com/lancetgh https://doi.org/10.1016/S2214-109X(15)70094-X

[5] Hopkins, K. (2000) Are Brazilian Women Really Choosing to Deliver by Cesarean? Social Science \& Medicine, 51, 725-740. https://doi.org/10.1016/S0277-9536(99)00480-3

[6] Diniz, S.G. and Chacham, A.S. (2004) "The Cut above" and "the Cut Below": The Abuse of Caesareans and Episiotomy in São Paulo, Brazil. Reproductive Health Matters, 12, 100-110. https://doi.org/10.1016/S0968-8080(04)23112-3 
[7] Lumbiganon, P., Laopaiboon, M., Gülmezoglu, A.M., Souza, J.P., Taneepanichskul, S., Ruyan, P., et al. (2010) Method of Delivery and Pregnancy Outcomes in Asia: The WHO Global Survey on Maternal and Perinatal Health 2007-08. The Lancet, 375, 490-499. https://doi.org/10.1016/S0140-6736(09)61870-5

[8] Villar, J., Valladares, E., Wojdyla, D., Zavaleta, N., Carroli, G., Velazco, A., et al. (2006) Caesarean Delivery Rates and Pregnancy Outcomes: The 2005 WHO Global Survey on Maternal and Perinatal Health in Latin America. The Lancet, 367, 1819-1829. https://doi.org/10.1016/S0140-6736(06)68704-7

[9] Shah, A., Fawole, B., M'imunya, J.M., Amokrane, F., Nafiou, I., Wolomby, J.J., et al. (2009) Cesarean Delivery Outcomes from the WHO Global Survey on Maternal and Perinatal Health in Africa. International Journal of Gynecology \& Obstetrics, 107, 191-197. https://doi.org/10.1016/j.ijgo.2009.08.013

[10] Torloni, M.R., Betran, A.P., Souza, J.P., Widmer, M., Allen, T., Gulmezoglu, M., et al. (2011) Classifications for Cesarean Section: A Systematic Review. PLoS ONE, 6, e14566. https://doi.org/10.1371/journal.pone.0014566

[11] Betran, A.P., Vindevoghel, N., Souza, J.P., Gulmezoglu, A.M. and Torloni, M.R. (2014) A Systematic Review of the Robson Classification for Caesarean Section: What Works, Doesn't Work and How to Improve It. PLOS ONE, 9, e97769. https://doi.org/10.1371/journal.pone.0097769

[12] Robson, M., Hartigan, L. and Murphy, M. (2013) Methods of Achieving and Maintaining an Appropriate Caesarean Section Rate. Best Practice \& Research Clinical Obstetrics \& Gynaecology, 27, 297-308. https://doi.org/10.1016/j.bpobgyn.2012.09.004

[13] Atchade, J. and Adisso, S. (2006) La césarienne: Intervention chirurgicale anodine ou dangereuse? Fondation Genevoise pour la formation et la recherche médicales. http://www.gfmer.ch/Membres_GFMER/pdf/Cesarienne_Adisso_2006.pdf

[14] Saizonou, J., De Brouwere, V., Vangeenderhuysen, C., Dramaix-Wilmet, M., Buekens, P. and Dujardin, B. (2006) Audit of the Quality of Treatment of "Near Miss" Patients in Referral Maternities in Southern Benin. Sante, 16, 33-42.

[15] Sossa Jérôme, C., Sopoh, G.E., Ogoudjobi, O.M., Issoufou Namassa, F., et al. (2017) Exemption from Health Care Fees Influences Indications of Caesarean Section in a Urban Health District Hospital in Benin. Universal Journal of Public Health, 5, 105-109. https://doi.org/10.13189/ujph.2017.050304

[16] Ouedraogo, T.L., Kpozehouen, A., Glegle-Hessou, Y., Makoutode, M., Saizonou, J. and Tchama-Bouraima, M. (2013) Evaluation de la mise en œuvre de la gratuite de la cesarienne au Benin. Sante Publique, 25, 507-515. https://doi.org/10.3917/spub.134.0507

[17] Witter, et al. (2016) Cost and Impact of Policies to Remove and Reduce Fees for Obstetric Care in Benin, Burkina Faso, Mali and Morocco. International Journal for Equity in Health, 15, 123. https://doi.org/10.1186/s12939-016-0412-y

[18] Müller, M., Kolly, L., Bauman, M., Imboden, S. and Surbek, D. (2014) Analysis of Caesarean Section Rates over Time in a Single Swiss Centre Using a Ten-Group Classification System. Swiss Medical Weekly, 144, w13921. https://doi.org/10.4414/smw.2014.13921

[19] Florica, M., Stephansson, O. and Nordström, L. (2006) Indications Associated with Increased Cesarean Section Rates in a Swedish Hospital. International Journal of Gynecology and Obstetrics, 92, 181-185. https://doi.org/10.1016/j.ijgo.2005.10.016

[20] Stjernholm, Y.V., Petersson, K. and Eneroth, E. (2010) Changed Indications for Cesarean Sections. Acta Obstetricia et Gynecologica, 89, 49-53. 
https://doi.org/10.3109/00016340903418777

[21] Ehrenthal, D.B., Jiang, X. and Strobino, D.M. (2010) Labor Induction and the Risk of a Cesarean Delivery among Nulliparous Women at Term. Obstetrics \& Gynecology, 116, 35-42. https://doi.org/10.1097/AOG.0b013e3181e10c5c

[22] Stavrou, et al. (2011) Epidemiology and Trends for Caesarean Section Births in New South Wales, Australia: A Population-Based Study. BMC Pregnancy and Childbirth, 11, 8. https://doi.org/10.1186/1471-2393-11-8

[23] Leone, T., et al. (2008) Community Factors Affecting Rising Caesarian Sections Rates in Developing Countries: An Analysis of Six Countries. Social Science and Medicine, 67, 1236-1246. https://doi.org/10.1016/j.socscimed.2008.06.032

[24] Kabore, C., Chaillet, N., Kouanda, N., Bujold, E., Traore, M. and Dumont, A. (2015) Maternel and Perinatal Outcomes Associated with a Trial of Labour after Previous Caesarian Section in Sub Saharan Countries. BJOG, 123, 2147-2155. https://doi.org/10.1111/1471-0528.13615

[25] Zhang, J., Troendle, J., Reddy, U.M., Laughon, S.K., Branch, D.W., Burkman, R., et al. (2010) Contemporary Cesarean Delivery Practice in the United States. American Journal of Obstetrics \& Gynecology, 203, 326 e321-326 e310.

https://doi.org/10.1016/j.ajog.2010.06.058

[26] Macones, G.A. (2008) Clinical Outcomes in VBAC Attempts: What to Say to Patients? American Journal of Obstetrics \& Gynecology, 199, 1-2. https://doi.org/10.1016/j.ajog.2008.03.040

[27] Landon, M.B., Hauth, J.C., Leveno, K.J., Spong, C.Y., Leindecker, S., Varner, M.W., et al. (2004) Maternal and Perinatal Outcomes Associated with a Trial of Labor after Prior Cesarean Delivery. The New England Journal of Medicine, 351, 2581-2589. https://doi.org/10.1056/NEJMoa040405

[28] Landon, M.B. (2008) Vaginal Birth after Cesarean Delivery. Clinics in Perinatology, 35, 491-504. https://doi.org/10.1016/j.clp.2008.07.004 